\title{
An update on the use of pantoprazole as a treatment for gastroesophageal reflux disease
}

This article was published in the following Dove Press journal:

Clinical and Experimental Gastroenterology

19 January 2010

Number of times this article has been viewed

\section{Sony Mathews \\ Ashley Reid \\ Chenlu Tian \\ Qiang Cai}

Division of Digestive Diseases, Department of Medicine, Emory University, School of Medicine,

Atlanta, GA, USA
Correspondence: Qiang Cai Division of Digestive Diseases, I365 Clifton Road, Suite BI262, Emory University, School of Medicine, Atlanta, GA 30322, USA

Tel + I 4047275638

Fax +I 4047275767

Email qcai@emory.edu

\begin{abstract}
Gastroesophageal reflux disease (GERD) is a chronic, recurrent disease that affects nearly 19 million people in the US. The mainstay of therapy for GERD is acid suppression. Proton pump inhibitors (PPIs) are the most effective medication for both initial treatment and maintenance therapy of GERD. Pantoprazole, a first-generation PPI, was approved by the FDA in 2000 for the treatment of erosive esophagitis associated with GERD. It has been used in more than 100 different countries worldwide. It is one of the few PPIs available in multiple forms: a delayed-release oral capsule, oral suspension, and intravenous. Pantoprazole been shown to improve acid reflux-related symptoms, heal esophagitis, and improve health-related quality of life more effectively than histamine-2 receptor antagonists. Evaluated in over 100 clinical trials, pantoprazole has an excellent safety profile, is as efficacious as other PPIs, and has a low incidence of drug interactions. It has also been shown to be safe and effective in special patient populations, such as the elderly and those with renal or moderate liver disease.
\end{abstract}

Keywords: pantoprazole, GERD, esophagitis

\section{Introduction to gastroesophageal reflux disease}

In 2006, the Montreal Consensus Group provided a global evidence-based definition of gastroesophageal reflux disease (GERD) as "a condition which develops when the reflux of stomach contents [into the esophagus] causes troublesome symptoms and/or complications". ${ }^{1}$ It is a chronic, often relapsing disease that if not treated appropriately can lead to further complications including esophageal ulcers, stricture formation, obstruction, Barrett's, and esophageal cancer. In addition, GERD can potentially lead to extra-esophageal complications, such as worsening asthma-like symptoms and chest pain. ${ }^{2}$ Reports indicate that GERD affects an estimated 19 million people in the US alone. This figure is likely to be an under-representation as many patients are misdiagnosed and subsequently not appropriately treated. ${ }^{3}$ Patients with GERD report a worse quality of life than those with diabetes, hypertension, mild heart failure, and angina. ${ }^{4-6}$

Based on the 2005 practice guidelines, the mainstay of therapy for GERD is acid suppression. ${ }^{7}$ Over the last 30 years, there has been an influx of various agents aimed at adequately controlling acid secretion and subsequently the symptoms of GERD. Since the discovery of the proton pump in the early 1970s and the subsequent development of proton pump inhibitors (PPIs); the mechanism by which GERD is treated has been revolutionized. ${ }^{8}$ In 1989, omeprazole entered the market as the first PPI to treat acid reflux. ${ }^{9}$ Then in 2000, pantoprazole became the fourth PPI marketed in the US and the first PPI to be available in both oral and intravenous (iv) forms. ${ }^{10}$ 


\section{Introduction of pantoprazole and its indications}

After 8 years of research, Wyeth Pharmaceuticals introduced pantoprazole in April, 1985. ${ }^{8}$ By 1994, pantoprazole was already in use throughout Europe but Food and Drug Administration (FDA) approval for use in the US did not occur until $2000^{8}$ (Table 1). Initially, pantoprazole was approved for treatment and maintenance of erosive esophagitis ( $40 \mathrm{mg}$ /day for 8 to 16 weeks). ${ }^{9}$ Later in 2001, pantoprazole iv was approved for short-term treatment (7 to 10 days) of GERD patients and a history of erosive esophagitis (40 mg/day) who are unable to tolerate oral pantoprazole. ${ }^{11}$ Since then, the indications for pantoprazole have expanded to include a variety of gastric acid-related diseases, including peptic ulcer disease (PUD), NSAID-induced ulcer prevention, ZollingerEllison syndrome, and adjunctive therapy for Helicobacter pylori eradication. ${ }^{9}$

\section{Structure and physiology of pantoprazole}

Pantoprazole is a membrane permeable substituted benzimidazole derivative that decreases gastric acid secretion by irreversibly inhibiting the $\mathrm{H}+/ \mathrm{K}+-$ ATPase located within gastric parietal cells..$^{10,12,13}$ It has high tissue selectivity for the canalicular lumen of the parietal cell, which has a $\mathrm{pH}$ of $1 .{ }^{14}$ Like other PPIs, it is a weakly basic prodrug that accumulates within this highly acidic environment and becomes rapidly activated into a cationic sulfonamide..$^{10,13,15}$ The protonated form then covalently binds to specific cysteine residues on the $\mathrm{H}+\mathrm{K}+$ ATPase enzyme, thus irreversibly inactivating the pump. Compared to other PPIs, pantoprazole is less likely to become activated in neutral to moderately acidic environment s ( $\mathrm{pH} 3$ to 5). The narrow $\mathrm{pH}$ window prevents pantoprazole from acting at nontarget areas in the body, thus reducing adverse effects. ${ }^{10,14,16}$ In vitro studies have shown that pantoprazole may actually have a longer duration of action than other PPIs because it is the only PPI to bind both cysteine 813 and cysteine 882 , the more distal residue of the proton pump. ${ }^{14}$ Theoretically, the distal site is less accessible to agents such as glutathione or dithiothreitol that potentially reverse proton pump inhibition. ${ }^{17}$

\section{Pharmacokinetics of pantoprazole}

Pantoprazole follows dose linear pharmacokinetics. Oral pantoprazole has a bioavailability of $77 \%$ and its absorption is not affected by food or antacids. ${ }^{10}$ It is ultimately absorbed in the small bowel, resulting in a maximum serum concentration 2 to 3 hours postingestion. ${ }^{18}$ Therefore, pantoprazole is most effective when given prior to meals so it reaches peak serum levels when the maximum number of proton pumps are activated postprandially. ${ }^{11}$ Unlike other PPIs, the serum concentration of pantoprazole is not dose-dependent; serum concentration after 1 dose is similar to that after multiple doses. ${ }^{19}$ Pantoprazole is completely metabolized via the hepatic cytochrome P450 system by CYP2C19 and CYP3A4, and up to $80 \%$ of the inactive metabolites are eliminated via renal exctretion. ${ }^{11,12}$ The metabolism of pantoprazole is independent of the route of administration, with a half-life of approximately 1.1 hours. ${ }^{10}$ However in patients with a mutation in the gene encoding the CYP2C19 enzyme, the half-life may be up to 3 hours. ${ }^{20}$

\section{Efficacy and current findings of pantoprazole}

Numerous multicenter randomized control studies have shown pantoprazole to be more efficacious than histamine-2 receptor antagonists (H2RAs) as the first-line drug for both treatment and maintenance therapy of erosive esophagitis associated with GERD. ${ }^{10,21-24}$ Pantoprazole $40 \mathrm{mg}$ /day for 4 to 8 weeks is the optimal regimen for the treatment of moderate to severe GERD. ${ }^{25}$ Patients taking oral pantoprazole $40 \mathrm{mg}$ /day had higher endoscopically confirmed healing rates at 4 weeks and 8 weeks, respectively, when compared with patients taking ranitidine $150 \mathrm{mg}$ twice daily $(54.0 \%$ to $95.1 \%$ vs $20.0 \%$ to $66.7 \%$ and $75.0 \%$ to $98.8 \%$ vs $41.0 \%$ to $77.4 \%$, $P<0.001$ ) or nitzatadine (79\% vs $44 \%, P<0.001) .{ }^{10,19,22,26,27}$ Similarly, patients taking pantoprazole $40 \mathrm{mg}$ /day had higher endoscopic remission rates than rantidine $150 \mathrm{mg}$ twice daily

Table I FDA-approved indications for pantoprazole in the treatment of gastroesophageal reflux disease (GERD) in the US

\begin{tabular}{lllll}
\hline Year & Indication & Dosage & Route & Duration \\
\hline 2000 & Healing of erosive esophagitis & $40 \mathrm{mg}$ daily & po capsule & $8-16$ weeks \\
2000 & Maintenance of erosive esophagitis & $40 \mathrm{mg}$ daily & po capsule & Continuous \\
2001 & Erosive esophagitis with GERD unable to tolerate po & $40 \mathrm{mg}$ daily & iv & $7-10$ days \\
2007 & Erosive esophagitis with GERD unable to tolerate po capsule & $40 \mathrm{mg}$ daily & po suspension & Continuous \\
\hline
\end{tabular}

Abbreviations: FAD, US Food and Drug Administration; iv, intravenous; po, by mouth. 
(78.0\% to $82 \%$ vs $21.0 \%$ to $33 \%, P<0.001$ ) for maintenance therapy at 12 months. ${ }^{14,28}$

When compared to other PPIs, pantoprazole has similarly efficacy in both the initial treatment and maintenance therapy of GERD. A double-blind, randomized, control study showed that pantoprazole $40 \mathrm{mg}$ /day and esomeprazole $40 \mathrm{mg}$ /day produce equivalent intraesophageal $\mathrm{pH}$ profiles and both similarly decrease esophageal acidity to normal levels 6 to 24 hours postingestion. ${ }^{29}$ Endoscopic healing rates at 4 weeks and 8 weeks show no statistically significant differences when comparing pantoprazole $40 \mathrm{mg}$ /day to omeprazole $20 \mathrm{mg}$ /day, omeprazole multiple unit pellet system $40 \mathrm{mg}$ /day, and lansoprazole $30 \mathrm{mg} /$ day $^{30-32}$ For maintenance therapy, pantoprazole $20 \mathrm{mg} /$ day is equivalent to esomeprazole $20 \mathrm{mg}$ /day for both endoscopic healing rates and symptom control at both 6 months and 12 months. ${ }^{33,34}$

Pantoprazole has been shown to improve health-related quality of life more effectively than H2RAs and with similar efficacy to other PPIs. ${ }^{2,5,6,35}$ Patients taking pantoprazole $40 \mathrm{mg} /$ day had a greater percentage of symptom-free days at 12 months compared to patients taking ranitidine $150 \mathrm{mg}$ twice daily $(83 \%$ vs $58 \%, P<0.001) .{ }^{14}$ A similar study found pantoprazole to provide greater symptom relief than famotidine. ${ }^{23}$ Although the efficacy seems to be relatively similar when comparing pantoprazole to other PPIs, limited data indicate that pantoprazole has a faster onset of symptom relief in patients with mild GERD. ${ }^{36,37}$ Similarly, in a study comparing pantoprazole $40 \mathrm{mg}$ /day to esomeprazole $40 \mathrm{mg}$ /day, patients treated with pantoprazole experienced less symptom relapse $(51 \%$ vs $61 \%, P<0.05)$ and fewer symptomatic episodes $(56 \%$ vs $71 \%, P<0.01)$ at one week post treatment than the esomeprazole group. ${ }^{38}$ Pantoprazole $40 \mathrm{mg}$ /day has also been shown to provide more effective control of night-time symptoms of GERD compared to esomeprazole $40 \mathrm{mg} /$ day. ${ }^{39}$ In the above studies, symptoms evaluated include heartburn, odynophagia, dysphagia, and acid regurgitation. Pantoprazole has positive patient satisfaction rates in trials involving patient questionnaires aimed at evaluating health-related quality of life such as ReQuest, GERDyzer, and the GERD symptom frequency questionnaire (GSFQ). ${ }^{35,40,41}$

Since pantoprazole is effective in controlling symptoms related to GERD and improving health-related quality of life, interest has arisen in using pantoprazole on an as-needed basis, rather than every-day doses. This concept is known as on-demand therapy. Although not currently FDA approved, on-demand therapy with pantoprazole has been shown to be effective in the treatment of patients with mild GERD in randomized control studies. ${ }^{42-44}$ In one study, patients with GERD were initially treated for 4 weeks with pantoprazole $20 \mathrm{mg} /$ day, and subsequently received pantoprazole $20 \mathrm{mg} /$ day or $40 \mathrm{mg}$ /day for the following 6 months as needed for recurrent symptoms. A score was then calculated based on the patient's perceived average daily symptom load. At 6 months, the mean symptom load scores were significantly lower in the treatment groups than in the placebo group (pantoprazole $20 \mathrm{mg}$ : 2.91; pantoprazole $40 \mathrm{mg}$ : 2.71; placebo: 3.93$)(P<0.0001) .{ }^{44}$ There was no statistical difference between the two dosage groups of pantoprazole. Similarly, a study $(n=236)$ of on-demand therapy for mild GERD comparing pantoprazole $20 \mathrm{mg}$ to esomeprazole $20 \mathrm{mg}$ revealed heartburn symptoms to be less severe in the pantoprazole group. ${ }^{42,44}$

\section{Special administration considerations of pantoprazole}

Conventional pantoprazole is formulated as an enteric-coated, delayed-release tablet. However, pantoprazole is one of the few PPIs available in both iv and oral suspension form for the treatment of GERD in patients who are unable to tolerate the delayed-release capsule form. ${ }^{11}$ Pantoprazole iv, which was approved in 2001 by the FDA, has equivalent efficacy to oral pantoprazole in its ability to suppress gastric acid output. ${ }^{45}$ In 2007, the FDA also approved pantoprazole to be available in oral suspension form for the treatment of erosive esophagitis in patients unable to swallow capsules. Although studies are limited, a recent multicenter randomized control study $(\mathrm{N}=60)$ showed oral suspension pantoprazole to provide similar efficacy to oral capsules in suppressing gastric acid output. ${ }^{46}$

\section{Safety and tolerability of pantoprazole}

Short- and long-term clinical trials show oral pantoprazole 40 to $120 \mathrm{mg} /$ day to have an excellent safety profile. ${ }^{47}$ Studies ranging from 8 weeks to 4 years have shown the incidence of adverse effects to be as low as $1 \%$ to $3 \%{ }^{47,48}$ The most commonly reported side effects include diarrhea $(2 \%)$, headaches $(2 \%)$, nausea $(1 \%)$, and constipation $(1 \%)$. As with most PPIs, diarrhea is the most prevalent of these side effects. ${ }^{11}$ Isolated case reports have associated pantoprazole use with thrombocytopenia and acute interstitial nephritis. ${ }^{49-51}$ Recently, long-term PPI use has been shown to have increased class-associated incidence for hip fractures; however, no individual reports are available for pantoprazole. ${ }^{52}$ Adverse side effects reported in patients with GERD who receive iv 
pantoprazole include headache, nausea, dizziness, flushing, and pain at the site of injection; however, data on tolerability in this subset of patients are limited. ${ }^{53}$

Randomized, controlled, double-blind control trials in patients with GERD have shown that oral pantoprazole $40 \mathrm{mg} /$ day has a comparable tolerability profile to oral omeprazole $20 \mathrm{mg} /$ day and lansoprazole $30 \mathrm{mg} /$ day after 8 weeks of therapy. ${ }^{54,55}$ In addition, oral pantoprazole $40 \mathrm{mg}$ /day has similar tolerability comparing to H2RAs, such as ranitidine $300 \mathrm{mg} /$ day and famotidine $40 \mathrm{mg} /$ day. ${ }^{56}$ Like other PPIs, pantoprazole can cause elevated gastrin levels; however, no data have been published indicating a correlation between elevated gastrin levels and an increased risk for cancer. ${ }^{2,10}$

There have been a few reported significant adverse drug interactions between pantoprazole and other medications metabolized through the CYP450 system. Unlike omeprazole, which recently has been shown to decrease the antiplatelet activity of clopidogrel, and which is also metabolized by CYP450, pantoprazole does not affect clopidogrel efficacy. ${ }^{57}$ Given pantoprazole's lower incidence for drug interactions compared to other PPIs, it is both safe and effective for long-term treatment of acid-related disorders in the elderly, a population at increased risk for adverse interactions due to medications. In addition, older patients have a higher incidence of developing severe esophagitis and its complications. Their relapse rate is also higher than that of younger patients if therapy with a PPI is not continued. Pantoprazole is also well tolerated in patients with renal failure and mild to moderate liver dysfunction (CHILDS class A/B). However, it has a relative contraindication in patients with severe liver disease. ${ }^{11}$

\section{Conclusion and future targets}

The data reviewed here show that pantoprazole is both safe and effective in the initial treatment and maintenance therapy for the management of erosive and nonerosive GERD. It has superior efficacy to H2RAs and has relatively equivalent efficacy compared to other PPIs. It is efficacious for both esophageal healing and relief of symptoms associated with GERD. Pantoprazole's favorable side effect profile and low incidence of drug-drug interactions make it ideal for using in special patient populations, such as the elderly and those with renal failure and moderate liver dysfunction. Future targets for study include more extensive trials on the use of continuous iv pantoprazole in the treatment of severe erosive esophagitis and longterm studies on the safety and efficacy of oral suspension formulation. ${ }^{58}$ In addition, expanding FDA approval for the use of pantoprazole in children and adolescents is currently being considered. ${ }^{59,60}$

\section{Disclosures}

The authors declare no conflicts of interest.

\section{References}

1. Vakil N, van Zanten SV, Kahrilas P, Dent J, Jones R. The Montreal definition and classification of gastroesophageal reflux disease: a global evidence-based consensus. Am J Gastroenterol. 2006;101:1900-1920; quiz 1943.

2. Scholten T. Long-term management of gastroesophageal reflux disease with pantoprazole. Ther Clin Risk Manag. 2007;3:231-243.

3. Hollenz M, Stolte M, Labenz J. Prevalence of gastro-oesophageal reflux disease in general practice. Dtsch Med Wochenschr. 2002;127: 1007-1012.

4. Revicki DA, Wood M, Maton PN, Sorensen S. The impact of gastroesophageal reflux disease on health-related quality of life. Am J Med. 1998;104:252-258.

5. Enck P, Dubois D, Marquis P. Quality of life in patients with upper gastrointestinal symptoms: results from the Domestic/International Gastroenterology Surveillance Study (DIGEST). Scand J Gastroenterol Suppl. 1999;231:48-54.

6. Dimenas E, Glise H, Hallerback B, Hernqvist H, Svedlund J, Wiklund I. Quality of life in patients with upper gastrointestinal symptoms. An improved evaluation of treatment regimens? Scand J Gastroenterol. 1993;28:681-687.

7. DeVault KR, Castell DO. Updated guidelines for the diagnosis and treatment of gastroesophageal reflux disease. Am J Gastroenterol. 2005;100:190-200.

8. Fischer J, Ganellin CR. Analogue Based-Drug Discovery. 1st Edition. Wiley-VCH Verlag GmBh\&Co. 2006:115-136.

9. Poole P. Pantoprazole. Am J Health Syst Pharm. 2001;58: 999-1008.

10. Cheer SM, Prakash A, Faulds D, Lamb HM. Pantoprazole: an update of its pharmacological properties and therapeutic use in the management of acid-related disorders. Drugs. 2003;63:101-133.

11. Devault KR. Pantoprazole: a proton pump inhibitor with oral and intravenous formulations. Expert Rev Gastroenterol Hepatol. 2007; 1:197-205.

12. Shi S, Klotz U. Proton pump inhibitors: an update of their clinical use and pharmacokinetics. Eur J Clin Pharmacol. 2008;64: 935-951.

13. Sachs G. Proton pump inhibitors and acid-related diseases. Pharmacotheraphy. 1997;17:22-37.

14. Richter JE, Fraga P, Mack M, Sabesin SM, Bochenek W. Prevention of erosive oesophagitis relapse with pantoprazole. Aliment Pharmacol Ther. 2004;20:567-575.

15. Calabrese C, Fabbri A, DiFebo G. Long-term management of GERD in the elderly with pantoprazole. Clin Interv Aging. 2007;2:85-92.

16. Avner DL. Clinical experience with pantoprazole in gastroesophageal reflux disease. Clin Ther. 2000;22:1169-1185; discussion 1149-1150.

17. Shin JM, Sachs G. Restoration of acid secretion following treatment with proton pump inhibitors. Gastroenterology. 2002;123:1588-1597.

18. Hartmann M, Theiss U, Huber R, et al. Twenty-four-hour intragastric $\mathrm{pH}$ profiles and pharmacokinetics following single and repeated oral administration of the proton pump inhibitor pantoprazole in comparison to omeprazole. Aliment Pharmacol Ther. 1996;10:359-366.

19. Van Rensburg CJ, Honiball PJ, Van Zyl JH, et al. Safety and efficacy of pantoprazole $40 \mathrm{mg}$ daily as relapse prophylaxis in patients with healed reflux oesophagitis - a 2-year follow-up. Aliment Pharmacol Ther. 1999;13:1023-1028. 
20. Tanaka M, Ohkubo T, Otani K, et al. Stereoselective pharmacokinetics of pantoprazole, a proton pump inhibitor, in extensive and poor metabolizers of S-mephenytoin. Clin Pharmacol Ther. 2001;69: 108-113.

21. Kahrilas PJ, Shaheen NJ, Vaezi MF, et al. American Gastroenterological Association Medical Position Satement on the management of gastroesophageal refluz disease. Gastroenterology. 2008;135: 1383-1391.

22. Gallo S, Dibildox M, Moguel A, et al. Clinical superiority of pantoprazole over ranitidine in the treatment of reflux esophagitis grade II and III. A prospective, double-blind, double-placebo study. Mexican clinical experience. Mexican Pantoprazole Study Group. Rev Gastroenterol Mex. 1998;63:11-16.

23. Dammann H, Von Kleist. Efficacy and tolerability of pantoprazole versus ranitidine and famotidine in patients with gastro-oesopghageal reflux disease: multicentre, open, randomised, control studies. International Clinical Practice Series. 1997;15:23-29.

24. Kovacs TO, Wilcox CM, DeVault K, Miska D, Bochenek W. Comparison of the efficacy of panctoprazole vs nizatidine in the treatment of erosive oesophagtitis: a randomized active-controlled, double0blind study. Aliment Pharmacol Ther. 2002;16:2043-2052.

25. Richter JE, Bochenek W. Oral pantoprazole for erosive esophagitis: a placebo-controlled, randomized clinical trial. Pantoprazole US GERD Study Group. Am J Gastroenterology. 2000;95:3071-3080.

26. Meneghelli UG, Boaventura S, Moraes-Filho JP, et al. Efficacy and tolerability of pantoprazole versus ranitidine in the treatment of reflux esophagitis and the influence of Helicobacter pylori infection on healing rate. Dis Esophagus. 2002;15:50-56.

27. Armstrong D, Pare P, Pericak D, Pyzyk M. Symptom relief in gastroesophageal reflux disease: a randomized, controlled comparison of pantoprazole and nizatidine in a mixed patient population with erosive esophagitis or endoscopy-negative reflux disease. Am J Gastroenterol. 2001;96:2849-2857.

28. Metz DC, Bochenek WJ. Pantoprazole maintenance therapy prevents relapse of erosive oesophagitis. Aliment Pharmacol Ther. 2003;17: $155-164$

29. Simon B, Muller P, Pascu O, Gatz G, Sander P, Huber R, Mascher H. Intra-oesophageal $\mathrm{pH}$ profiles and pharmacokinetics of pantoprazole and esomeprazole: a crossover study in patients with gastrooesophageal reflux disease. Eur J Gastroenterol Hepatol. 2003;15 791-799.

30. Mulder CJ, Westerveld BD, Smit JM, et al. A double-blind, randomized comparison of omeprazole Multiple Unit Pellet System (MUPS) $20 \mathrm{mg}$, lansoprazole $30 \mathrm{mg}$ and pantoprazole $40 \mathrm{mg}$ in symptomatic reflux oesophagitis followed by 3 months of omeprazole MUPS maintenance treatment: a Dutch multicentre trial. Eur J Gastroenterol Hepatol. 2002;14:649-656.

31. Glatzel D, Abdel-Qader M, Gatz G, Pfaffenberger B. Pantoprazole $40 \mathrm{mg}$ is as effective as esomeprazole $40 \mathrm{mg}$ to relieve symptoms of gastroesophageal reflux disease after 4 weeks of treatment and superior regarding the prevention of symptomatic relapse. Digestion. 2006;74: $145-154$

32. Koerner T. Comparable efficacy of pantoprazole $40 \mathrm{mg}$ vs omeprazole MUPS $40 \mathrm{mg}$ in patients with GERD II/III. Gut. 2002;51:A166.

33. Goh KL, Benamouzig R, Sander P, Schwan T. Efficacy of pantoprazole $20 \mathrm{mg}$ daily compared with esomeprazole $20 \mathrm{mg}$ daily in the maintenance of healed gastroesophageal reflux disease: a randomized, doubleblind comparative trial-the EMANCIPATE study. Eur J Gastroenterol Hepatol. 2007;19:205-211.

34. Laurtisen. Comparable efficacy of pantoprazole and omeprazole to prevent relapse in patients with GERD. Gut. 2000;47 Suppl III:39(A60).

35. Holtmann $G$. International validation of a health-related quality of life questionnaire in patients with erosive gastro-oesophageal reflux disease. Aliment Pharmacol Ther. 2009;29:615-625.

36. Scholten T. Pantoprazole $40 \mathrm{mg}$ relieves primary reflux symptoms more rapidly than omeprazole MUPS $20 \mathrm{mg}$ in patients with severe GERD symptomatology. Gastroenterology. 2000;118:A1303.
37. Ehrlich A, Luecker PW, Wiedemann A, Sander P, Huber R, Mascher H Comparison of the pharmacodynamics and pharmacokinetics of pantoprazole (40 mg) as compared to omeprazole MUPS (20 mg) after repeated oral dose administration. Methods Find Exp Clin Pharmacol. 1999;21:47-51.

38. Thomson A. Impact of PPIs on patient focused symptomatology in GERD. Ther Clin Risk Manag. 2008;4:1185-1200.

39. Orr WC. Night-time gastro-oesophageal reflux disease: prevalence, hazards, and management. Eur J Gastroenterol Hepatol. 2005;17: 113-120.

40. Pare P, Armstrong D, Pericak D, Pyzyk M. Pantoprazole rapidly improves health-related quality of life in patients with heartburn: a prospective, randomized, double blind comparative study with nizatidine. J Clin Gastroenterol. 2003;37:132-138.

41. Bardhan KD, Stanghellini V, Armstrong D, Berghofer P, Gatz G, Monnikes H. International validation of ReQuest in patients with endoscopy-negative gastro-oesophageal reflux disease. Digestion. 2007; 75 Suppl 1:48-54.

42. Scholten T, Teutsch I, Bohuschke M, Gatz G. Pantoprazole on-demand effectively treats symptoms in patients with gastro-oesophageal reflux disease. Clin Drug Investig. 2007;27:287-296.

43. Kaspari S, Kupcinskas L, Heinze H, Berghofer P. Pantoprazole 20 mg on demand is effective in the long-term management of patients with mild gastro-oesophageal reflux disease. Eur J Gastroenterol Hepatol. 2005;17:935-941.

44. Scholten T, Dekkers CP, Schutze K, Korner T, Bohuschke M, Gatz G. On-demand therapy with pantoprazole $20 \mathrm{mg}$ as effective long-term management of reflux disease in patients with mild GERD: the ORION trial. Digestion. 2005;72:76-85.

45. Metz DC, Pratha V, Martin P, et al. Oral and intravenous dosage forms of pantoprazole are equivalent in their ability to suppress gastric acid secretion in patients with gastroesophageal reflux disease. Am J Gastroenterol. 2000;95:626-633.

46. Hogan D, Pratha V, Riff D, et al. Oral pantoprazole in the form of granules or tablets are pharmacodynamically equivalent in suppressing acid output in patients with gastro-oesophageal reflux disease and a history of erosive oesophagitis. Aliment Pharmacol Ther. 2007;26:249-256.

47. Fitton A, Wiseman L. Pantoprazole. A review of its pharmacological properties and therapeutic use in acid-related disorders. Drugs. 1996;51:460-482.

48. Martin de Argila C. Safety of potent gastric acid inhibition. Drugs. 2005;65 Suppl 1:97-104.

49. Moore I, Sayer JA, Nayar A, Ahmed S, Tapson JS. Pantoprazole-induced acute interstitial nephritis. J Nephrol. 2004;17:580-581.

50. Ra A, Tobe SW. Acute interstitial nephritis due to pantoprazole. Ann Pharmacother. 2004;38:41-45.

51. Watson TD, Stark JE, Vesta KS. Pantoprazole-induced thrombocytopenia. Ann Pharmacother. 2006;40:758-761.

52. Targownik LE, Lix LM, Metge CJ, Prior HJ, Leung S, Leslie WD. Use of proton pump inhibitors and risk of osteoporosis-related fractures. CMAJ. 2008;179:319-326.

53. Pratha V, Hogan DL, Lynn RB, Field B, Metz DC. Intravenous pantoprazole as initial treatment in patients with gastroesophageal reflux disease and a history of erosive esophagitis: a randomized clinical trial. Dig Dis Sci. 2006;51:1595-1601.

54. Dupas JL, Houcke P, Samoyeau R. Pantoprazole versus lansoprazole in French patients with reflux esophagitis. Gastroenterol Clin Biol. 2001;25:245-250.

55. Corinaldesi R, Valentini M, Belaiche J, Colin R, Geldof H, Maier C. Pantoprazole and omeprazole in the treatment of reflux oesophagitis: a European multicentre study. Aliment Pharmacol Ther. 1995;9:667-671.

56. Scholten T, Hahn EG, Bosseckert H, et al. Clinical tolerability of pantoprazole compared with ranitidine and famotidine. International Clinicial Practice Series. 1997;15:31-36.

57. Siller-Matula JM, Spiel AO, Lang IM, Kreiner G, Christ G, Jilma B. Effects of pantoprazole and esomeprazole on platelet inhibition by clopidogrel. Am Heart J. 2009;157:148e1-e5. 
58. Cai Q, Barrie M, Olejeme H, Roserberg M. A Pilot Study of Efficacy and Safety of Continuous Intravenous Infusion of Pantoprazole in the Treatment of Severe Erosive Esophagitis. Dig Dis Sci. 2008;53: $1500-1505$.

59. Tsou VM, Baker R, Book L, et al. Multicenter, randomized, double-blind study comparing 20 and $40 \mathrm{mg}$ of pantoprazole for symptom relief in adolescents (12 to 16 years of age) with gastroesophageal reflux disease (GERD). Clin Pediatr (Phila). 2006;45:741-749.
60. Tolia V, Bishop PR, Tsou VM, Gremse D, Soffer EF, Comer GM. Multicenter, randomized, double-blind study comparing 10,20 and $40 \mathrm{mg}$ pantoprazole in children (5-11 years) with symptomatic gastroesophageal reflux disease. J Pediatr Gastroenterol Nutr. 2006;42:384-391.

\section{Publish your work in this journal}

Clinical and Experimental Gastroenterology is an international, peerreviewed, open access journal, publishing all aspects of gastroenterology in the clinic and laboratory, including: Pathology, pathophysiology of gastrointestinal disease; Investigation and treatment of gastointestinal disease; Pharmacology of drugs used in the alimentary tract;
Immunology/genetics/genomics related to gastrointestinal disease. This journal is indexed on CAS. The manuscript management system is completely online and includes a very quick and fair peer-review system. Visit http://www.dovepress.com/testimonials.php to read real quotes from published authors.

Submit your manuscript here: http://www.dovepress.com/clinical-and-experimental-gastroenterology-journal 